\title{
Phase IB Study of Sorafenib and Evofosfamide in Patients with Advanced Hepatocellular and Renal Cell Carcinomas (NCCTG N1135, Alliance)
}

\section{Nguyen Tran}

Mayo Clinic https://orcid.org/0000-0002-6104-6489

\section{Nathan Foster}

Mayo Clinic Minnesota

\section{Amit Mahipal}

Mayo Clinic Minnesota

Thomas Byrne

Mayo Clinic Arizona

Joleen Hubbard

Mayo Clinic Minnesota

\section{Alvin Silva}

Mayo Clinic Arizona

Kabir Mody

Mayo Clinic's Campus in Florida

\section{Steven Alberts}

Mayo Clinic Rochester: Mayo Clinic Minnesota

Mitesh Borad ( $\sim$ Borad.Mitesh@mayo.edu )

Mayo Clinic Arizona

\section{Research Article}

Keywords: evofosfamide, hypoxia activated pro-drug (HAP), hepatocellular cancer

Posted Date: February 24th, 2021

DOI: https://doi.org/10.21203/rs.3.rs-234613/v1

License: (c) (i) This work is licensed under a Creative Commons Attribution 4.0 International License. Read Full License

Version of Record: A version of this preprint was published at Investigational New Drugs on March 1st, 2021. See the published version at https://doi.org/10.1007/s10637-021-01090-w. 


\section{Abstract}

Background: Sorafenib (Sor) remains a first-line option for hepatocellular carcinoma (HCC) or refractory renal cell carcinomas (RCC). PLC/PRF/5 HCC model showed upregulation of hypoxia with enhanced efficacy when Sor is combined with hypoxia-activated prodrug evofosfamide (Evo).

Methods: This phase IB $3+3$ design investigated 3 Evo dose levels $\left(240,340,480 \mathrm{mg} / \mathrm{m}^{2}\right.$ on days $\left.8,15,22\right)$, combined with Sor $200 \mathrm{mg}$ orally twice daily (po bid) on days 1-28 of a 28-day cycle. Primary objectives included determining maximum tolerated dose (MTD) and recommended phase ll dose (RP2D) of Sor + Evo.

Results: Eighteen patients were enrolled (median age 62.5 years; 17 male / 1 female; 12 HCC/6 RCC) across three dose levels (DL0: Sor $200 \mathrm{mg}$ bid/Evo 240 mg/m² [n=6], DL1:Sor $200 \mathrm{mg}$ bid/Evo 480 mg/m² [n=5], DL1a: Sor 200 $\mathrm{mg} \mathrm{bid/Evo} 340 \mathrm{mg} / \mathrm{m}^{2}$ [n=7]). Two dose-limiting toxicities (DLTs) were reported with Evo $480 \mathrm{mg} / \mathrm{m}^{2}$ (grade 3 mucositis, grade 4 hepatic failure). Grade 3 rash DLT was observed in one patient at Evo $240 \mathrm{mg} / \mathrm{m}^{2}$. No DLTs were observed at Evo $340 \mathrm{mg} / \mathrm{m}^{2}$. MTD and RP2D were established as Sor $200 \mathrm{mg} / \mathrm{Evo} 340 \mathrm{mg} / \mathrm{m}^{2}$ and Sor $200 / E v o ~ 240 \mathrm{mg} / \mathrm{m}^{2}$, respectively. The most common treatment-related adverse events included fatigue, hand-foot syndrome, hypertension, and nausea/vomiting. Two partial responses were observed, one each at DL0 and DL1a.; disease control rate was $55 \%$.

Conclusions: RP2D was established as sorafenib $200 \mathrm{mg}$ bid + Evo $240 \mathrm{mg} / \mathrm{m}^{2}$. While preliminary anti-tumor activity was observed, future development must account for advances in immunotherapy in HCC/RCC.

NCT01497444

Date of registration December 20, 2011

\section{Introduction}

Hepatocellular carcinoma (HCC) remains one of the deadliest cancers globally. Currently, it is the fourth leading cause of cancer death worldwide.(1) Patients often present with advanced disease when first diagnosed. Since 2007, sorafenib, an oral multikinase inhibitor, has been established as first line systemic therapy for patients with advanced HCC. This is based on the results of a phase III clinical trial (SHARP) where Llovet and colleagues randomized 602 patients to sorafenib or placebo. Patients on the sorafenib arm demonstrated an improvement in overall survival (OS) (10.7 versus 7.9 months; hazard ratio (HR), 0.69; 95\% Cl, 0.55-0.87; $\mathrm{P}<0.001)$. (2) Survival benefits were observed in a separate trial in patients in the Asia-Pacific region.(3) Recent advances in systemic treatments have led to longer survival; the combination atezolizumab and bevacizumab resulted in 12-month survival rates of $67.2 \%$ compared to $54.6 \%$ in the sorafenib arm.(4) However, responses remain short for the majority of patients with refractory disease.(5-7) Additional therapeutic options in this setting are urgently needed.

New cases of renal cell carcinoma (RCC) affect more than 70,000 individuals in the US(8) and 300,000 individuals worldwide yearly.(9) The 5-year survival for patients with distant metastatic disease is low at 13\%.(10) Since 2005, targeted therapies utilizing tyrosine kinase inhibitors (TKIs), anti-VEGF antibodies as well as mammalian target of rapamycin (mTOR) have been used in first- and second-line treatments. The addition of immune checkpoint inhibitors has further improved the overall response rate and progression-free survival (PFS) in selected 
populations. $(11,12)$ However, the majority of patients progress on these therapies and as such, there remains a significant unmet need.

Hypoxia has been well characterized in $\mathrm{HCC}(13)$ and $\mathrm{RCC}(14)$ and is associated with worsening prognosis. Hypoxia has been postulated to promote genomic instability, acceleration and accumulation of mutations(15) that confer drug resistance and lead to invasive and metastatic potential. High proportions of solid tumors with hypoxic regions showed resistance to radiation and conventional chemotherapy due to inability to penetrate beyond 50-100 $\mu \mathrm{m}$ from capillaries. $(16,17)$ Therapeutics designed to target these areas may augment and complement the anti-tumor activity of standard drugs by exploiting tumor hypoxia through activation of a prodrug. This class of drug is designated as hypoxia activated prodrugs (HAPs).

TH-302 or evofosfamide (Evo), a second generation of HAPs, is a nitroimidazole-linked prodrug of a brominated version of isophosphoramide mustard (Br-IPM).(18) When exposed to hypoxic conditions, Evo is reduced at the nitroimadazole site by intracellular reductase leading to subsequent release of Br-IPM. Br-IPM then acts as a DNA crosslinking agent. In areas of normoxia, evofosfamide remains intact as prodrug and toxicity is minimized. Numerous preclinical and clinical studies have demonstrated its effect across different cancer types including HCC and RCC.(19-24) Preclinical studies using sorafenib in the PLC/PRF/5 HCC model showed upregulation of hypoxia in both HCC and RCC.(25) The addition of TH-302 to sorafenib showed delayed tumor growth compared to $\mathrm{TH}-302$ or sorafenib alone.

The current phase IB study was designed to determine the dose-limiting toxicities (DLTs) and maximum tolerated dose (MTD) of TH-302 and sorafenib in patients with advanced HCC and RCC.

\section{Methods}

\section{Study Design}

North Central Cancer Treatment Group (NCCTG) study N1135 was a phase I single-arm trial that used a classical $3+3$ dose escalation, followed by a maximum tolerated dose (MTD) dose-expansion design in patients with advanced HCC and RCC. The starting regimen was given as follows: sorafenib $200 \mathrm{mg}$ orally twice a day on days 1 to 28 and Evo $240 \mathrm{mg} / \mathrm{m} 2$ on days 8, 15 and 22 every 28 days. Dose escalation entailed Evo dosed at 340 $\mathrm{mg} / \mathrm{m} 2$ and $480 \mathrm{mg} / \mathrm{m} 2$. Three patients were treated at each dose level, and were observed for a minimum of 4 weeks to assess for toxicities before new patients were treated. DLT was defined as adverse event attributed to the study treatment in the first four weeks of combination therapy. DLTs included febrile neutropenia, any grade 4 neutropenia lasting more than 7 days, grade 4 thrombocytopenia, grade 5 toxicity attributed to study treatment, any grade ischemic events and any nonhematologic adverse events grade 3 or greater lasting 14 days or more. Table $\mathrm{S} 1$ includes the full definition. Patients were treated until disease progression, unacceptable toxicity as defined by DLT, withdrawal of consent for treatment, physician decision or death. NCCTG is now part of the Alliance for Clinical Trials in Oncology.

\section{Patients}

Patients recruited were age 18 years and older, had cytological or histological confirmed diagnosis of advanced hepatocellular or renal cell carcinoma with an Eastern Cooperative Oncology Group (ECOG) performance status of 0 or 1. HCC patients had Child Pugh A or B7 liver disease and were not amenable to surgery or orthotopic liver transplant. Patients with prior first-line treatment with sorafenib were allowed. RCC patients had received standard 
approved first-line therapy only. Adequate blood and organ function, as well as measurable disease per Response Evaluation Criteria in Solid Tumors (RECIST) version 1.1 were required for inclusion. Patients were excluded if they had active malignancy within 3 years prior to registration, were pregnant or nursing women, had inadequately controlled hypertension, prolonged QTc $>500 \mathrm{msec}$ on baseline electrocardiogram, fibrolamellar histology HCC or mixed hepatocholangiocarcinoma, hepatic sarcomas and other non-HCC primary liver tumors (See S2 for full protocol). The study protocol was approved by the institutional review board at each study site. All patients signed an IRB-approved, protocol-specific written informed consent document in accordance with federal and institutional guidelines.

\section{Assessments}

The primary end-point was the incidence of DLTs assessed in cycle 1 (DLTs are defined in Supplementary Table S1). A minimum of 3 patients were enrolled in each consecutive dosing cohort. If DLTs occurred in more than or equal to two of 6 patients, the dose was de-escalated. Safety was continuously evaluated by incidence and severity of treatment emergent adverse events according to National Cancer Institute Common Terminology Criteria for Adverse Events version 4.0. After treatment discontinuation, each patient was followed for disease progression and survival for up to 3 years after registration. The objective response rate was assessed by computed tomography or magnetic resonance imaging according to RECIST v1.1 criteria.

\section{Statistical Methodology}

Primary objectives were to determine the MTD and recommended phase II dose (RP2D) of combination sorafenib and Evo. Secondary objectives included assessment of overall safety profile, confirmed response rate based on RECIST 1.1 criteria, progression-free survival (PFS) and overall survival (OS). PFS was defined as the time from registration to death due to any cause or disease progression. OS was defined as the time from registration to death due to any cause. Kaplan-Meier methodology(26) and the log-rank test were used to describe the distribution of PFS and OS by dose level. Continuous data was compared across the dose levels via the Kruskal-Wallis test and categorical data were compared across dose levels using the Fisher's exact test. All analyses of secondary data were highly exploratory given the small sample sizes at each dose level. Two-sided p-values $<0.05$ were considered statistically significant and SAS 9.4 was used for statistical analysis. Data collection and statistical analyses were conducted by the Alliance Statistics and Data Center. Data quality was ensured by review of data by the Alliance Statistics and Data Center and by the study chairperson following Alliance policies. All analyses were based on the study database frozen on [December 4, 2020].

\section{Results}

\section{Patient disposition}

A total of 24 patients were enrolled across the 3 dose levels from June 2012 to December 2015, of which 18 were treated and evaluable for response. All patients have discontinued treatment, with the majority discontinuing due to adverse events $(n=8,44 \%)$, followed by disease progression $(n=6,33 \%)$ and withdrawal by patients $(n=3,17 \%)$. One death occurred on study (grade 5 esophageal hemorrhage that occurred during cycle 3 ) and was not related to study treatment. The median follow-up was 24.5 months (range: 17.2-31.7).

\section{Baseline characteristics}


Patient demographics and baseline characteristics are described in Table 1 and S2. The median age was 62.5 years and most patients (94.4\%) were male. Twelve patients had diagnosis of HCC, while 6 had RCC. For HCC patients, the majority of patients had cirrhosis (83.3\%), median Child Pugh score of 6, and median albumin of 3.6 $\mathrm{g} / \mathrm{dL}$. Most patients did not receive prior locoregional therapy including chemoembolization $(75.0 \%)$ or tumordirected therapy $(66.7 \%)$.

\section{Safety}

Patients were enrolled across three dose levels: 0, 1 and +1 a. Table 2 summarizes the safety of all treatment levels. At dose level 0, one DLT occurred during cycle 1 with grade 3 papulopustular rash possibly related to treatment. Two patients experienced DLT with dose level 1: grade 3 oral and anal mucositis definitely related to treatment and grade 4 hepatic failure possibly related to treatment. No DLT was observed at dose level +1 a.

The observed grade 3 or higher AE rate was higher for dose level $1(60 \%)$ compared to the other dose levels (50\% dose level 0,29\% dose level 1a, respectively). Due to small numbers, this was not statistically significant (Fisher's exact $p=0.60)$. The most common treatment-related adverse events (TRAEs) were fatigue $(n=11)$, hand-foot syndrome $(n=7)$, hypertension $(n=7)$, nausea/vomiting $(n=7)$, weight loss $(n=5)$, oral mucositis $(n=4)$, diarrhea $(n=4)$, and rash $(n=4)$ (Table 3). There were no treatment-related deaths. The MTD was established at evosfosfamide of $340 \mathrm{mg} / \mathrm{m} 2$ and sorafenib $200 \mathrm{mg}$ BID. The RP2D was evofosfamide $240 \mathrm{mg} / \mathrm{m}^{2}$ and sorafenib $200 \mathrm{mg}$ bid, 1 level below MTD.

\section{Treatment exposure}

For dose level 0, 6 patients received a median of 3.5 cycles (range 1-6). For dose level 1, median of cycles received was 2 (range: 1-4). Of the 7 eligible patients enrolled to dose level $+1 \mathrm{a}$, median number of cycles was 2 (range 111). Across all patients, the median number of treatment cycles received was 2 cycles (range: 1-11).

\section{Efficacy}

Preliminary evidence of anti-tumor activity was observed with the combination. Two partial responses (one unconfirmed) were noted $(2 / 18,11.1 \%)$. The disease control rate defined as partial response plus complete response and stable disease was, 55.6\% (10/18) (Table S3). Further exploratory analyses were conducted by dose level and by tumor type. The median progression-free survival for all 3 groups were 3.6 months $(95 \% \mathrm{Cl}, 2.6-21.0)$ for dose level 0, 2.0 months $(95 \% \mathrm{Cl}, 1.8-4.1)$ for dose level 1, and 7.8 months $(95 \% \mathrm{Cl}, 2.4-24.6)$ for dose level $+1 \mathrm{a}$, (Fig. 1) ( $p=0.0191)$. The median overall survival was 18.5 months $(95 \% \mathrm{Cl}, 4.9-22.3)$ for dose level $0,23.7$ months (95\% Cl, 6.9-NE) for dose level 1, and 13.4 months (95\% Cl, 5.7-24.6) for dose level $+1 \mathrm{a}$, (Fig. 2), ( $p=0.2782)$. There are 2 patients still alive of the 18 eligible patients. Of these 2 patients, the median follow-up was 24.5 months (range: 17.2-31.7). The overall median PFS across all 18 eligible patients was 3.6 months (95\% Cl: 2.1-17.4) (see Fig S1). The overall median OS across all 18 eligible patients was 17.9 months (95\% Cl: 6.9-24.6) (see Fig S2). Within HCC only, the overall median PFS was 6.3 months (95\% Cl: 2.1-NE) and the overall median 0 S was 13.9 months (95\% Cl: 4.9-NE) (Figures S3-S4).

\section{Discussion}

Hypoxia is a known feature of many tumors including HCC and RCC. Tumor cells have the capability to survive and thrive in the setting of hypoxia through metabolic reprogramming(27-29), gene expressions that suppress 
apoptosis(30) and enhancing receptor tyrosine kinase signaling (31) among many other key mechanisms. Through these mechanisms, hypoxic regions of tumor play an important role in tumor progression and development of aggressive phenotypes and are implicated in resistance to therapy.(32) Several bioreductive prodrugs have been designed to target tumor hypoxia for the treatment of cancer(33); however, results have been disappointing.(34-36)

Antiangiogenics are established therapeutics in HCC and RCC. One major drawback includes exacerbating hypoxia due to reduction in tumor vasculature. HAPs such as TH-302 can overcome this limitation by targeting hypoxic regions. In this phase I trial, we evaluated the safety and dose-limiting toxicity of the combination of sorafenib and Evo in patients with advanced HCC and RCC. Results from this study established sorafenib dosing of $200 \mathrm{mg}$ BID and evosfosfamide of $340 \mathrm{mg} / \mathrm{m} 2$ as the MTD.

The combination from this study is feasible in patients with HCC and RCC after first-line therapy. The most common side effects included fatigue, hand-foot syndrome, hypertension, nausea/vomiting, weight loss, oral mucositis, diarrhea, and rash. These are consistent with side effects seen previously with single agent sorafenib(2) and Evo.(37) Grade 3 or higher AEs (regardless of attribution) were observed in $29 \%$ of patients receiving MTD dose and were manageable. The rate of treatment discontinuation in this study was $44 \%$, similar to that of single agent use of sorafenib at 38\%.(2) The recommended phase Il dose was established at Evo $240 \mathrm{mg} / \mathrm{m}^{2}$ and sorafenib $200 \mathrm{mg}$ bid, 1 level below MTD. This dose level was more tolerable, as more patients were able to stay on treatment longer with median of 3.5 cycles of treatment with range from 1-6. Patients on MTD level stayed on treatment for a median of 2 cycles (range from 1-11).

The efficacy results from this study are encouraging, with $11 \%$ having a partial response and a disease control rate of $55 \%$. Median progression-free survival was 7.8 months and 3.6 months for MTD and RP2D cohorts, respectively. Median OS was 13.4 months for MTD cohort and 18.5 months for RP2D. These results are consistent with survival outcomes seen in other second-line therapy in HCC.(5-7) This study demonstrates preliminary safety and tolerability of the combination sorafenib with TH-302 in patients with HCC and RCC. Efficacy was observed and there is a rationale for continuation to the phase II portion at the RP2D.

Since the completion of this trial, the treatment paradigm for HCC has changed, with the U.S. Food and Drug Administration approval of atezolizumab in combination with bevacizumab as the standard first-line therapy. This presents new opportunities for novel combinations. Evosfosfamide has successfully been combined with a number of other antiangiogenic agents including pazopanib(38), bevacizumab(39), and sunitinib(40). Preclinical data suggest synergism when evosfosfamide is combined with immune checkpoint inhibitors in solid tumors.(41) Studies in preclinical mouse models showed decreased frequency and density of myeloid-derived suppressor cells with reduction of hypoxia. Indirect and direct tumor-infiltrating T cells benefits were observed with increased proliferation, cytotoxicity, cytokine production and survival. The combination of evosfosfamide and ipilimumab, a CTLA-4 inhibitor, is currently being evaluated across solid tumors in clinical trials (NCT03098160). Based on this rationale, future combinations could be considered with evosfosfamide, atezolizumab with bevacizumab in the first-line setting in HCC.

In parallel, the treatment landscape for RCC has also changed dramatically with the addition of the combinations pembrolizumab plus axitinib, avelumab plus axitinib, and ipilimumab plus nivolumab as front line therapies for both favorable and unfavorable risk groups. $(11,12,42)$ More recently, tivozanib, a selective inhibitor of VEGFR, improved PFS in patients previously treated with checkpoint inhibitor plus VEGFR TKI or VEGFR TKIs alone.(43) 
Given the preclinical data suggesting synergism when evosfosfamide is combined with immune checkpoint inhibitors, the next step is to either combine evosfosfamide with immune checkpoint inhibitors plus anti-VEGFR in the front-line setting or combine evosfosfamide with tivozanib in the refractory renal cell carcinoma setting.

Given these advances in the therapeutic paradigm for advanced HCC and RCC, future development of HAPs such as evofosfamide would need to be in post-immune checkpoint inhibitor settings if doublets with antiangiogenics are evaluated further. In the first-line setting, feasibility would need to be established with triplet combinations involving HAPs, antiangiogenic and immune checkpoint inhibitors, and further development would be contingent on safety feasibility and meaningfully robust signals over established efficacy benchmarks in those settings.

ClinicalTrials.gov Identifier: NCT01497444

\section{Declarations}

\section{Funding:}

Research reported in this publication was supported by the National institutes of Health (NIH) of the National Institutes of Health under Award Numbers U10CA180821 and U10CA180882 (to the Alliance for Clinical Trials in Oncology), UG1CA232760, also through a DP2 award CA195764 (to MJB); and National Cancer Institute (NCI) K12 award CA090628 (to MJB). Also supported in part by Threshold Pharmaceuticals.

https://acknwledgments.alliancefound.org. Non-government funders had no role in the study design, data collection and analysis, decision to publish or preparation of the manuscript. The content is solely the responsibility of the authors and does not necessarily represent the official views of the National Institutes of Health.

The following institutional networks participated in this study: Mayo Clinic LAPS; Rochester, MN; Steven Alberts; UG1CA232760.

\section{Conflicts of interest:}

none

\section{Availability of data and material:}

not applicable

\section{Code availability:}

not applicable

\section{Authors' contributions:}

Mitesh Borad is responsible for conception and design of study, patient recruitment, draft and review of manuscript.

Nguyen Tran is responsible for data analysis and interpretation, draft and review of manuscript.

Nathan Foster is responsible for statistical analysis. 
Remaining authors contributed to patient recruitment and review of manuscript.

Ethics approval:

not applicable

\section{Consent to participate:}

The study protocol was approved by the institutional review board at each study site. All patients signed an IRBapproved, protocol-specific written informed consent document in accordance with federal and institutional guidelines.

\section{Consent for publication:}

not applicable

\section{Acknowledgements:}

not applicable

\section{References}

1. Akinyemiju T, Abera S, Ahmed M, Alam N, Alemayohu MA, Allen C, et al. The Burden of Primary Liver Cancer and Underlying Etiologies From 1990 to 2015 at the Global, Regional, and National Level. JAMA Oncology. 2017;98121(12):1683-91.

2. Llovet JM, Ricci S, Mazzaferro V, Hilgard P, Gane E, Blanc JF, et al. Sorafenib in advanced hepatocellular carcinoma. N Engl J Med. 2008;359(4):378-90.

3. Cheng AL, Kang YK, Chen Z, Tsao CJ, Qin S, Kim JS, et al. Efficacy and safety of sorafenib in patients in the Asia-Pacific region with advanced hepatocellular carcinoma: a phase III randomised, double-blind, placebocontrolled trial. Lancet Oncol. 2009;10(1):25-34.

4. Finn RS, Qin S, Ikeda M, Galle PR, Ducreux M, Kim TY, et al. Atezolizumab plus Bevacizumab in Unresectable Hepatocellular Carcinoma. N Engl J Med. 2020;382(20):1894-905.

5. Abou-Alfa GK, Meyer T, Cheng AL, El-Khoueiry AB, Rimassa L, Ryoo BY, et al. Cabozantinib in Patients with Advanced and Progressing Hepatocellular Carcinoma. N Engl J Med. 2018;379(1):54-63.

6. Finn RS, Ryoo BY, Merle P, Kudo M, Bouattour M, Lim HY, et al. Pembrolizumab As Second-Line Therapy in Patients With Advanced Hepatocellular Carcinoma in KEYNOTE-240: A Randomized, Double-Blind, Phase III Trial. J Clin Oncol. 2020;38(3):193-202.

7. Zhu AX, Kang YK, Yen CJ, Finn RS, Galle PR, Llovet JM, et al. Ramucirumab after sorafenib in patients with advanced hepatocellular carcinoma and increased a-fetoprotein concentrations (REACH-2): a randomised, double-blind, placebo-controlled, phase 3 trial. The Lancet Oncology. 2019;20(2):282-96.

8. Siegel RL, Miller KD, Jemal A. Cancer statistics, 2019. CA Cancer J Clin. 2019;69(1):7-34.

9. Ferlay J, Soerjomataram I, Dikshit R, Eser S, Mathers C, Rebelo M, et al. Cancer incidence and mortality worldwide: sources, methods and major patterns in GLOBOCAN 2012. Int J Cancer. 2015;136(5):E359-86.

10. National Cancer Institute. Cancer stat facts: kidney and renal pelvis cancer. https://seer.cancer.gov/statfacts/html/kidrp.html [accessed November 20, 2020]. 
11. Motzer RJ, Tannir NM, McDermott DF, Arén Frontera O, Melichar B, Choueiri TK, et al. Nivolumab plus Ipilimumab versus Sunitinib in Advanced Renal-Cell Carcinoma. New England Journal of Medicine. 2018;378(14):1277-90.

12. Rini BI, Plimack ER, Stus V, Gafanov R, Hawkins R, Nosov D, et al. Pembrolizumab plus Axitinib versus Sunitinib for Advanced Renal-Cell Carcinoma. New England Journal of Medicine. 2019;380(12):1116-27.

13. Lee TK, Poon RT, Yuen AP, Ling MT, Wang XH, Wong YC, et al. Regulation of angiogenesis by Id-1 through hypoxia-inducible factor-1alpha-mediated vascular endothelial growth factor up-regulation in hepatocellular carcinoma. Clin Cancer Res. 2006;12(23):6910-9.

14. Kaelin Jr WG. The von Hippel-Lindau tumour suppressor protein: 02 sensing and cancer. Nature Reviews Cancer. 2008;8(11):865-73.

15. Gillies RJ, Gatenby RA. Hypoxia and adaptive landscapes in the evolution of carcinogenesis. Cancer Metastasis Rev. 2007;26(2):311-7.

16. Höckel M, Vaupel P. Tumor hypoxia: definitions and current clinical, biologic, and molecular aspects. J Natl Cancer Inst. 2001;93(4):266-76.

17. Minchinton Al, Tannock IF. Drug penetration in solid tumours. Nat Rev Cancer. 2006;6(8):583-92.

18. Duan JX, Jiao H, Kaizerman J, Stanton T, Evans JW, Lan L, et al. Potent and highly selective hypoxia-activated achiral phosphoramidate mustards as anticancer drugs. J Med Chem. 2008;51(8):2412-20.

19. Harms JK, Lee TW, Wang T, Lai A, Kee D, Chaplin JM, et al. Impact of Tumour Hypoxia on Evofosfamide Sensitivity in Head and Neck Squamous Cell Carcinoma Patient-Derived Xenograft Models. Cells. 2019;8(7).

20. Huang Y, Tian Y, Zhao Y, Xue C, Zhan J, Liu L, et al. Efficacy of the hypoxia-activated prodrug evofosfamide (TH-302) in nasopharyngeal carcinoma in vitro and in vivo. Cancer Communications. 2018;38(1):15.

21. Liapis V, Zinonos I, Labrinidis A, Hay S, Ponomarev V, Panagopoulos V, et al. Anticancer efficacy of the hypoxia-activated prodrug evofosfamide (TH-302) in osteolytic breast cancer murine models. Cancer Med. 2016;5(3):534-45.

22. Borad MJ, Reddy SG, Bahary N, Uronis HE, Sigal D, Cohn AL, et al. Randomized Phase II Trial of Gemcitabine Plus TH-302 Versus Gemcitabine in Patients With Advanced Pancreatic Cancer. J Clin Oncol. 2015;33(13):1475-81.

23. Chawla SP, Cranmer LD, Van Tine BA, Reed DR, Okuno SH, Butrynski JE, et al. Phase II study of the safety and antitumor activity of the hypoxia-activated prodrug TH-302 in combination with doxorubicin in patients with advanced soft tissue sarcoma. Journal of clinical oncology : official journal of the American Society of Clinical Oncology. 2014;32(29):3299-306.

24. Ganjoo KN, Cranmer LD, Butrynski JE, Rushing D, Adkins D, Okuno SH, et al. A phase I study of the safety and pharmacokinetics of the hypoxia-activated prodrug TH-302 in combination with doxorubicin in patients with advanced soft tissue sarcoma. Oncology. 2011;80(1-2):50-6.

25. Sun JD, Liu Q, Wang J, Ahluwalia D, Ferraro D, Wang Y, et al. Selective Tumor Hypoxia Targeting by HypoxiaActivated Prodrug TH-302 Inhibits Tumor Growth in Preclinical Models of Cancer. Clinical Cancer Research. 2012;18(3):758.

26. Kaplan EL, Meier P. Nonparametric Estimation from Incomplete Observations. Journal of the American Statistical Association. 1958;53:457-81.

27. Favaro E, Bensaad K, Chong MG, Tennant DA, Ferguson DJ, Snell C, et al. Glucose utilization via glycogen phosphorylase sustains proliferation and prevents premature senescence in cancer cells. Cell Metab. 
2012;16(6):751-64.

28. Riganti C, Gazzano E, Polimeni M, Aldieri E, Ghigo D. The pentose phosphate pathway: an antioxidant defense and a crossroad in tumor cell fate. Free Radic Biol Med. 2012;53(3):421-36.

29. Ros S, Schulze A. Balancing glycolytic flux: the role of 6-phosphofructo-2-kinase/fructose 2,6bisphosphatases in cancer metabolism. Cancer Metab. 2013;1(1):8.

30. Erler JT, Cawthorne CJ, Williams KJ, Koritzinsky M, Wouters BG, Wilson C, et al. Hypoxia-mediated downregulation of Bid and $\mathrm{Bax}$ in tumors occurs via hypoxia-inducible factor 1-dependent and -independent mechanisms and contributes to drug resistance. Mol Cell Biol. 2004;24(7):2875-89.

31. Wang Y, Ohh M. Oxygen-mediated endocytosis in cancer. J Cell Mol Med. 2010;14(3):496-503.

32. Wilson WR, Hay MP. Targeting hypoxia in cancer therapy. Nature Reviews Cancer. 2011;11(6):393-410.

33. Wigerup C, Påhlman S, Bexell D. Therapeutic targeting of hypoxia and hypoxia-inducible factors in cancer. Pharmacol Ther. 2016;164:152-69.

34. Rischin D, Peters LJ, O'Sullivan B, Giralt J, Fisher R, Yuen K, et al. Tirapazamine, cisplatin, and radiation versus cisplatin and radiation for advanced squamous cell carcinoma of the head and neck (TROG 02.02, HeadSTART): a phase III trial of the Trans-Tasman Radiation Oncology Group. J Clin Oncol. 2010;28(18):2989-95.

35. DiSilvestro PA, Ali S, Craighead PS, Lucci JA, Lee YC, Cohn DE, et al. Phase III randomized trial of weekly cisplatin and irradiation versus cisplatin and tirapazamine and irradiation in stages IB2, IIA, IIB, IIIB, and IVA cervical carcinoma limited to the pelvis: a Gynecologic Oncology Group study. J Clin Oncol. 2014;32(5):45864.

36. Tap WD, Papai Z, Van Tine BA, Attia S, Ganjoo KN, Jones RL, et al. Doxorubicin plus evofosfamide versus doxorubicin alone in locally advanced, unresectable or metastatic soft-tissue sarcoma (TH CR-406/SARC021): an international, multicentre, open-label, randomised phase 3 trial. Lancet Oncol. 2017;18(8):1089-103.

37. Weiss GJ, Infante JR, Chiorean EG, Borad MJ, Bendell JC, Molina JR, et al. Phase 1 study of the safety, tolerability, and pharmacokinetics of $\mathrm{TH}-302$, a hypoxia-activated prodrug, in patients with advanced solid malignancies. Clin Cancer Res. 2011;17(9):2997-3004.

38. Riedel RF, Meadows KL, Lee PH, Morse MA, Uronis HE, Blobe GC, et al. Phase I study of pazopanib plus TH302 in advanced solid tumors. Cancer Chemother Pharmacol. 2017;79(3):611-9.

39. Brenner A, Floyd J, Eng C, Kroll S, Fichtel L, Gruslova A, et al. AT-12: PHASE 1/2 STUDY OF TH-302, INVESTIGATIONAL HYPOXIA-ACTIVATED PRODRUG, AND BEVACIZUMAB IN PATIENTS WITH BEVACIZUMABREFRACTORY RECURRENT GLIOBLASTOMA. Neuro Oncol. 2014;16(Suppl 5):v10-v1.

40. Starodub A, Vaena D, Pennington KL, Kio EA, Bruetman D, Thorne T, et al. Abstract B77: Phase I study of TH302, an investigational hypoxia-targeted drug, in combination with sunitinib. Molecular Cancer Therapeutics. 2013;12(11 Supplement):B77.

41. Jayaprakash P, Ai M, Curran MA. Abstract IA11: Reversal of immunotherapy resistance through hypoxia reduction. Clinical Cancer Research. 2020;26(12 Supplement 2):IA11.

42. Motzer RJ, Penkov K, Haanen J, Rini B, Albiges L, Campbell MT, et al. Avelumab plus Axitinib versus Sunitinib for Advanced Renal-Cell Carcinoma. N Engl J Med. 2019;380(12):1103-15.

43. Rini BI, Pal SK, Escudier BJ, Atkins MB, Hutson TE, Porta C, et al. Tivozanib versus sorafenib in patients with advanced renal cell carcinoma (TIVO-3): a phase 3, multicentre, randomised, controlled, open-label study. Lancet Oncol. 2020;21(1):95-104. 


\section{Tables}

Page 11/16 
Table 1

Demographics and Baseline Characteristics ( $N=18)$

\begin{tabular}{|c|c|c|c|c|c|}
\hline & $\begin{array}{l}\text { Dose level } \\
0 \\
\text { [Sor } \\
200 / \text { Evo } \\
240] \\
(\mathrm{N}=6)\end{array}$ & $\begin{array}{l}\text { Dose level } \\
1 \\
\text { [Sor } \\
200 / \text { Evo } \\
480] \\
(\mathrm{N}=5)\end{array}$ & $\begin{array}{l}\text { Dose level } \\
+1 \mathrm{a} \\
{[\mathrm{Sor}} \\
200 / \text { Evo } \\
340] \\
(\mathrm{N}=7)\end{array}$ & $\begin{array}{l}\text { Total } \\
(\mathrm{N}=18)\end{array}$ & $\mathrm{p}$ value \\
\hline Age (years) & & & & & $0.1094^{1}$ \\
\hline Mean (SD) & $68.0(11.8)$ & $55.4(8.6)$ & $66.4(10.2)$ & $63.9(11.2)$ & \\
\hline Median & 71.0 & 55.0 & 62.0 & 62.5 & \\
\hline Range & $\begin{array}{l}(47.0- \\
80.0)\end{array}$ & $\begin{array}{l}(43.0- \\
66.0)\end{array}$ & $\begin{array}{l}(58.0- \\
86.0)\end{array}$ & $(43.0-86.0)$ & \\
\hline Gender & & & & & $0.6111^{2}$ \\
\hline Female & $1(16.7 \%)$ & $0(0.0 \%)$ & $0(0.0 \%)$ & $1(5.6 \%)$ & \\
\hline Male & $5(83.3 \%)$ & $5(100.0 \%)$ & $7(100.0 \%)$ & $17(94.4 \%)$ & \\
\hline Race & & & & & $0.3595^{2}$ \\
\hline White & $4(66.7 \%)$ & $5(100.0 \%)$ & $7(100.0 \%)$ & $16(88.9 \%)$ & \\
\hline Black or African American & $1(16.7 \%)$ & $0(0.0 \%)$ & $0(0.0 \%)$ & $1(5.6 \%)$ & \\
\hline Native Hawaiian or Other Pacific Islander & $1(16.7 \%)$ & $0(0.0 \%)$ & $0(0.0 \%)$ & $1(5.6 \%)$ & \\
\hline Tumor Type & & & & & $0.3194^{2}$ \\
\hline RCC & $2(33.3 \%)$ & $3(60.0 \%)$ & $1(14.3 \%)$ & $6(33.3 \%)$ & \\
\hline $\mathrm{HCC}$ & $4(66.7 \%)$ & $2(40.0 \%)$ & $6(85.7 \%)$ & $12(66.7 \%)$ & \\
\hline ECOG PS & & & & & $0.2390^{2}$ \\
\hline 0 & $0(0.0 \%)$ & $2(40.0 \%)$ & $1(14.3 \%)$ & $3(16.7 \%)$ & \\
\hline 1 & $6(100.0 \%)$ & $3(60.0 \%)$ & $6(85.7 \%)$ & $15(83.3 \%)$ & \\
\hline Disease Status & & & & & $1.0000^{2}$ \\
\hline Not applicable & 2 & 3 & 1 & 6 & \\
\hline Intrahepatic & $2(50.0 \%)$ & $1(50.0 \%)$ & $2(33.3 \%)$ & $5(41.7 \%)$ & \\
\hline Extrahepatic & $2(50.0 \%)$ & $1(50.0 \%)$ & $4(66.7 \%)$ & $7(58.3 \%)$ & \\
\hline Vascular Invasion & & & & & $0.4192^{2}$ \\
\hline Not applicable & 2 & 3 & 1 & 6 & \\
\hline Yes & $3(75.0 \%)$ & $0(0.0 \%)$ & $2(33.3 \%)$ & $5(41.7 \%)$ & \\
\hline
\end{tabular}




\begin{tabular}{|c|c|c|c|c|c|}
\hline No & $1(25.0 \%)$ & $2(100.0 \%)$ & $4(66.7 \%)$ & $7(58.3 \%)$ & \\
\hline History of Cirrhosis & & & & & $1.0000^{2}$ \\
\hline Not applicable & 2 & 3 & 1 & 6 & \\
\hline Yes & $3(75.0 \%)$ & $2(100.0 \%)$ & $5(83.3 \%)$ & $10(83.3 \%)$ & \\
\hline No & $1(25.0 \%)$ & $0(0.0 \%)$ & $1(16.7 \%)$ & $2(16.7 \%)$ & \\
\hline Hepatitis B & & & & & $0.6225^{2}$ \\
\hline Yes & $1(16.7 \%)$ & $2(40.0 \%)$ & $1(14.3 \%)$ & $4(22.2 \%)$ & \\
\hline No & $5(83.3 \%)$ & $3(60.0 \%)$ & $6(85.7 \%)$ & $14(77.8 \%)$ & \\
\hline Hepatitis C & & & & & $0.0476^{2}$ \\
\hline Yes & $2(33.3 \%)$ & $0(0.0 \%)$ & $5(71.4 \%)$ & $7(38.9 \%)$ & \\
\hline No & $4(66.7 \%)$ & $5(100.0 \%)$ & $2(28.6 \%)$ & $11(61.1 \%)$ & \\
\hline Alcohol Related & & & & & $0.3824^{2}$ \\
\hline Yes & $1(16.7 \%)$ & $0(0.0 \%)$ & $3(42.9 \%)$ & $4(22.2 \%)$ & \\
\hline No & $5(83.3 \%)$ & $5(100.0 \%)$ & $4(57.1 \%)$ & $14(77.8 \%)$ & \\
\hline $\mathrm{NASH}$ & & & & & NA \\
\hline No & $6(100.0 \%)$ & $5(100.0 \%)$ & $7(100.0 \%)$ & $18(100.0 \%)$ & \\
\hline Other Etiology & & & & & NA \\
\hline No & $6(100.0 \%)$ & $5(100.0 \%)$ & $7(100.0 \%)$ & $18(100.0 \%)$ & \\
\hline Prior Chemoembolization & & & & & $0.3455^{2}$ \\
\hline Not applicable & 2 & 3 & 1 & 6 & \\
\hline Yes & $0(0.0 \%)$ & $1(50.0 \%)$ & $2(33.3 \%)$ & $3(25.0 \%)$ & \\
\hline No & $4(100.0 \%)$ & $1(50.0 \%)$ & $4(66.7 \%)$ & $9(75.0 \%)$ & \\
\hline Previous Tumor Directed Therapy & & & & & $0.2687^{2}$ \\
\hline Not applicable & 2 & 3 & 1 & 6 & \\
\hline Yes & $0(0.0 \%)$ & $1(50.0 \%)$ & $3(50.0 \%)$ & $4(33.3 \%)$ & \\
\hline No & $4(100.0 \%)$ & $1(50.0 \%)$ & $3(50.0 \%)$ & $8(66.7 \%)$ & \\
\hline
\end{tabular}


Table 2

Safety of All Dose Levels

\begin{tabular}{|c|c|c|}
\hline $\begin{array}{l}\text { Dose Level } 0 \\
\text { (Sor 200/Evo 240) }\end{array}$ & $\begin{array}{l}\text { Dose Level } 1 \\
\text { (Sor 200/Evo 480) }\end{array}$ & $\begin{array}{l}\text { Dose Level }+1 a \\
\text { (Sor 200/vo 340) }\end{array}$ \\
\hline 1 DLT in 6 Eligible patients & 2 DLTs in 5 Eligible patients & $\begin{array}{l}0 \text { DLTs in } 7 \text { Eligible } \\
\text { patients }\end{array}$ \\
\hline 3 of 6 with Grade $3+A E(50 \%)$ & 3 of 5 with Grade $3+$ AEs $(60 \%)$ & $\begin{array}{l}2 \text { of } 7 \text { with Grade } 3 \\
+A E(29 \%)\end{array}$ \\
\hline $\begin{array}{l}2 \text { of } 6 \text { with Grade } 3+\mathrm{AE}(33 \%) \\
\text { at least possibly related to } \\
\text { treatment }\end{array}$ & $\begin{array}{l}3 \text { of } 5 \text { with Grade } 3+\mathrm{AEs}(60 \%) \text {, at least possibly } \\
\text { related to treatment }\end{array}$ & $\begin{array}{l}1 \text { of } 7 \text { with Grade } 3 \\
+\mathrm{AE}(14 \%) \text {, at least } \\
\text { possibly related }\end{array}$ \\
\hline \multirow{2}{*}{$\begin{array}{l}1 \text { DLT happened cycle } 1 \text { (Grade } \\
3 \text { papulopustular rash - } \\
\text { possibly related to treatment) }\end{array}$} & $\begin{array}{l}\text { DLT 1) Grade } 4 \text { Hepatic failure DLT that occurred } \\
\text { during cycle } 1 \text { (possibly related to treatment). }\end{array}$ & \\
\hline & $\begin{array}{l}\text { DLT 2) Grade } 3 \text { Mucositis oral (definitely related) } \\
\text { and a Grade } 3 \text { anal mucositis (definitely related) } \\
\text { during cycle } 1 \text {, that was definitely a DLT }\end{array}$ & \\
\hline
\end{tabular}

Table 3

Safety, AEs at least possibly related $(\mathrm{N}=18)$

\begin{tabular}{|llll|}
\hline & Any Grade & Grade 1 or 2 & Grade 3 or higher \\
\hline Fatigue & $11(61.1)$ & $11(61.1)$ & \\
\hline Nausea/vomiting & $7(38.9)$ & $7(38.9)$ & \\
\hline Hypertension & $7(38.9)$ & $6(33.3)$ & $1(5.6)$ \\
\hline Hand-foot syndrome & $7(38.9)$ & $5(27.8)$ & $2(11.1)$ \\
\hline Weight loss & $5(27.8)$ & $5(27.8)$ & \\
\hline Diarrhea & $4(22.2)$ & $4(22.2)$ & \\
\hline Rash & $4(22.2)$ & $3(16.7)$ & $1(5.6)$ \\
\hline Oral Mucositis & $4(22.2)$ & $2(11.1)$ & $2(11.1)$ \\
\hline AE; adverse events & & & \\
\hline
\end{tabular}

\section{Figures}




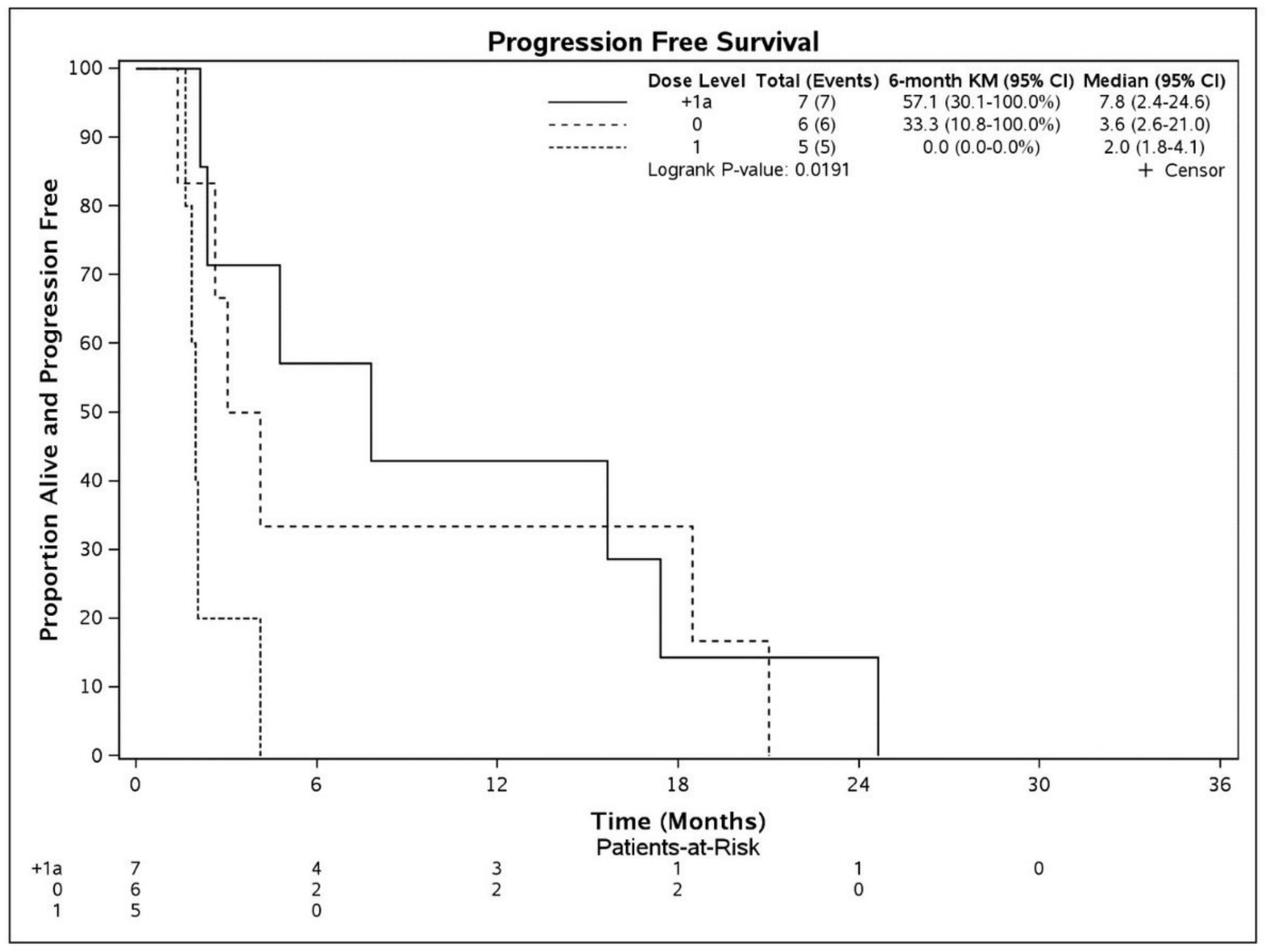

Figure 1

Progression-Free Survival by Dose Level* . *Kaplan-Meier analysis was performed 


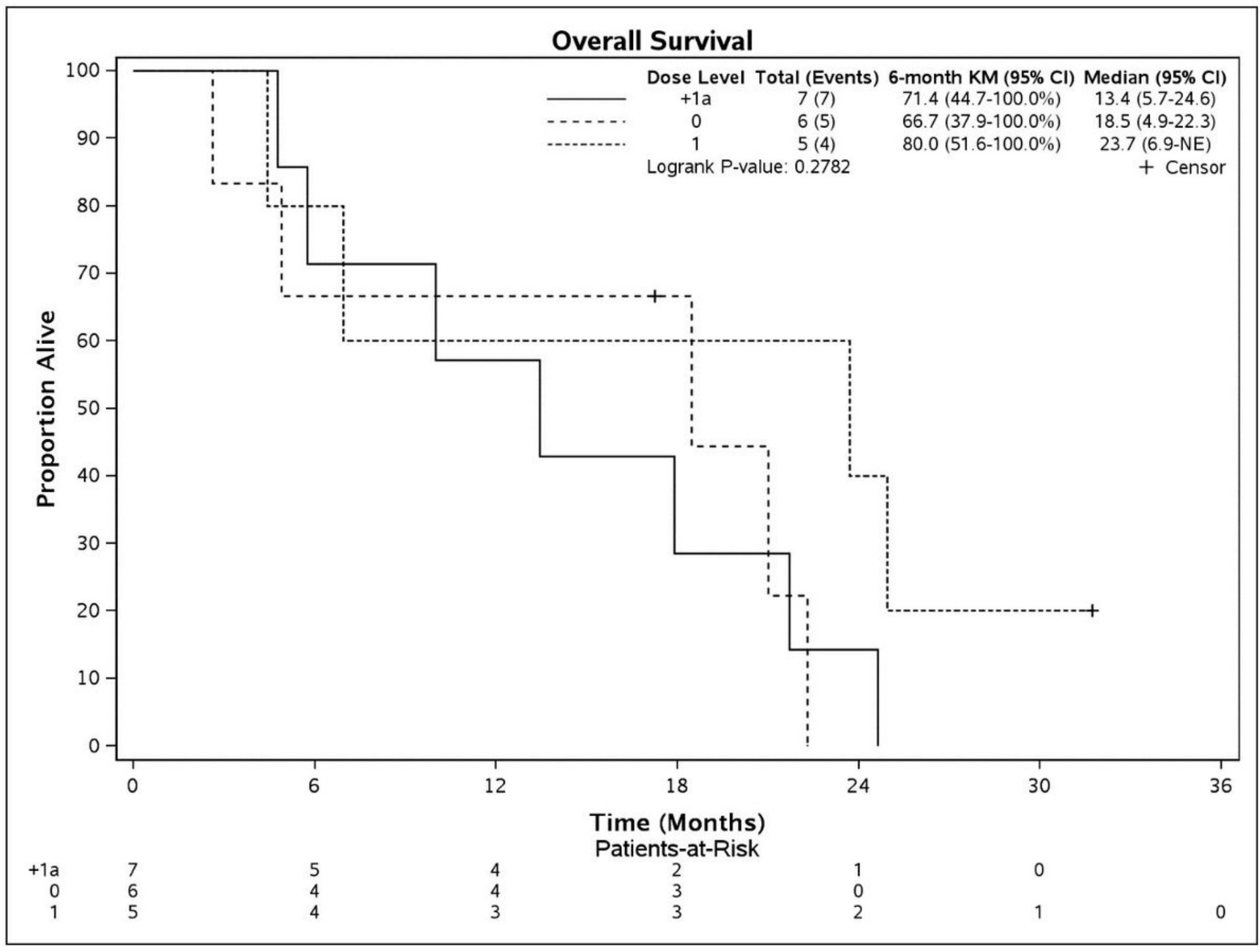

Figure 2

Overall Survival by Dose Level*. *Kaplan-Meier analysis was performed

\section{Supplementary Files}

This is a list of supplementary files associated with this preprint. Click to download.

- Supplementfiguresandtables.docx 